\title{
Bias voltage influence on the mechanical and tribological properties of titanium aluminum nitride coatings produced by triode magnetron sputtering
}

\author{
Diana Marcela Devia Narvaez ${ }^{1}$, Juan Manuel Velez Restrepo ${ }^{2}$ \\ Elisabeth Restrepo Parra ${ }^{3}$
}

\author{
${ }^{1}$ Universidad Tecnológica de Pereira, Pereira, Colombia \\ e-mail: dianadevia@gmail.com, \\ ${ }^{2}$ Universidad Nacional de Colombia Sede Medellín, Laboratorio de Materiales \\ e-mail:jmvelez@unal.edu.co \\ ${ }^{3}$ Universidad Nacional de Colombia Sede Manizales, PCM Computational Applications \\ e-mail: erestrepopa@unal.edu.co
}

\begin{abstract}
$\mathrm{Ti}_{\mathrm{X}} \mathrm{Al}_{1-\mathrm{x}} \mathrm{N}$ coatings were grown using the triode magnetron sputtering technique with various bias voltages between $-40 \mathrm{~V}$ and $-150 \mathrm{~V}$. As the bias voltage increased, an increase in the Al atomic percentage was observed, presenting a competition with $\mathrm{Ti}$ and producing structural changes. Moreover, the grain size and roughness were also strongly influenced by the bias voltage. It was observed that coatings with concentrations of approximately $25 \% \mathrm{Al}$ and $75 \% \mathrm{Ti}$ exhibited an optimum mixture of mechanical and tribological properties. The average coefficient of friction was low for the TiAlN coating that was grown at $-40 \mathrm{~V}$. Additionally, the critical load was obtained by measuring the adhesion using the scratch test.
\end{abstract}

Keywords: Bias voltage, Coefficient of friction, Adhesion, Hardness.

\section{INTRODUCTION}

Recently, there has been considerable interest in the testing of micro- and nanoscale contacts to study the performance of tribological contacts for the development of nano- and micro-devices and to measure the responses of materials under conditions that are representative of asperities in macroscale contacts [1]. This analysis is important for wear-resistant hard coatings, which are currently needed in the modern manufacturing industry to achieve good-performance cutting tools [2] . In the past few years, TiAlN coatings obtained from physical vapor deposition (PVD) techniques have been widely used to improve the lifetime and performance of a wide variety of tool materials with attractive properties, such as a high degree of hardness, good wear and chemical stability [3]. Titanium aluminum nitride films deposited on various metallic and PM materials have been shown to be effective in many applications, including machining, dry metal forming and molding, oxidation, wear- and corrosion-resistant materials at high temperatures, biocompatible surgical implants and prosthesis and dental alloys [4]. One of the most widely used PVD techniques is sputtering, which has undergone several modifications over time to improve the deposition processes. One of the sputtering technique improvements is triode magnetron sputtering (TMS). Compared to diode magnetron sputtering, TMS enhances the ionization rate by introducing a polarized grid in front of the target. RECCO et al. [ $\underline{5}$ reported TiN that was produced by this technique. The authors found that a higher homogeneity resulted from the greater electron collection by the grid. Additionally, among other characteristics, denser films for lower substrate temperatures and a compact film structure for temperatures of approximately $300{ }^{\circ} \mathrm{C}$ were observed. Although TiAlN films have been produced by several techniques, such as cathodic pulsed arc [6], magnetron sputtering [7] and laser ablation [8], no works on the growth of TiAlN by TMS have been reported in the literature. However, it is well known that the physical and chemical properties of films that are grown by magnetron sputtering depend strongly on the processing parameters, such as the pressure, temperature and bias voltage. Of particular importance is the substrate bias voltage, which controls the ion bombardment energy on the growing film and plays a crucial role in determining the properties of the coating [9]. 
It is well known that control of the film morphology, the mechanical and tribological properties are achieved via variations in the substrate bias potential, which in turn, modify the energy of the depositing ions. Typically, for a deposition process, the substrates are negatively biased in the range of 0 to $300 \mathrm{~V}$ in reference to the anode potential [10]. The bias voltage during the coating process is a highly influential parameter because it controls the energy of the impacting ions. Therefore, this voltage is also a well-known tool for influencing several coating properties. PETROV et al. reported on the influence of the impinging ion energy on the predominant orientation of TiN and TiAlN [11]. With increasing ion energy, the texture changed from (111) to (200). Moreover, the bombardment caused a continuous re-nucleation due to the disturbance of the local epitaxial growth. LJUNGCRANTZ et al. reported on the influence of the bias voltage on residual stresses $[\underline{12}, \underline{13}]$. At low bias voltages, from 0 to $-100 \mathrm{~V}$, the residual compressive stress increased due to an increase in the defect density. At bias voltages of $-150 \mathrm{~V}$ and higher, the predominant effect was the induced mobility of the atoms due to ion bombardment. This effect led to decreasing residual stresses because of the enhanced annihilation of defects. ZHAO et al. reported that, with increasing bias voltage, the Al content in TiAlN coatings decreased, whereas the residual compressive stresses and hardness increased up to $-100 \mathrm{~V}$ and decreased with higher bias voltages [14]. Similar results were also published by other authors $[15,16]$. In a previous work, we studied TiAlN coatings that were grown by a triode magnetron sputtering system by increasing the bias voltage. The influence of the bias voltage on the microstructure, composition and mechanical properties was investigated. A higher concentration of $\mathrm{Al}$ atoms was observed with increasing bias voltage. According to the XRD analysis, crystallographic orientations in the $\{111\},\{200\},\{220\}$ and $\{311\}$ planes were found, and a competition between the $\{111\}$ and $\{200\}$ planes was exhibited. Additionally, increases in the roughness and grain size were observed with increasing bias because of the increase in the ion flux/energy that was bombarding the surface. Moreover, a decrease in the hardness and the adherence was observed when the bias voltage was increased because of the decrease in the film density [17]. Although there are many works that present the growth of TiAlN coatings, using several techniques and which study the influence of the deposition parameters, including the bias voltage, the TMS technique has not been commonly used. On the other hand, the bias voltage influence has not been analyzed sufficiently for the coatings that are produced by this technique, especially in the case of TiAlN coatings.

The aim of the present work is to deposit TiAlN coatings, using the triode magnetron sputtering technique to investigate the effect of the bias voltage on the coatings. We concentrate on the mechanical and tribological properties, i.e., the hardness, Young's modulus, coefficient of friction and wear resistance.

\section{EXPERIMENTAL SETUP}

TiAIN coatings were deposited on AISI O1 tool steel substrates with $12.5 \mathrm{~mm}$ of diameter and $3 \mathrm{~mm}$ of thickness, using a Ti0.5Al0.5 target by triode magnetron sputtering (TMS) in a non-commercial system [18]. The substrate temperature was remained constant at $300{ }^{\circ} \mathrm{C}$. A continuous gas flow of argon and nitrogen $\left(\mathrm{Ar}+\mathrm{N}_{2}\right)$ was injected into the chamber for the coating production. The most suitable $\mathrm{N}_{2}$ flow $(5 \mathrm{sccm})$ was obtained from the experimental hysteresis curve of pressure $(\mathrm{Pa})$ versus flow $(\mathrm{sccm})$ when keeping the argon flow constant at $20 \mathrm{sccm}$. At this flow value, target poisoning (material deposition on the target) was avoided, thus increasing the sputter yield and the film deposition. A vacuum pressure of $2.67 \times 10^{-4} \mathrm{~Pa}$ was reached, and a working pressure of $0.4 \mathrm{~Pa}$ was used. The films were grown for 60 min with a current of $2 \mathrm{~A}$ and a bias voltage of $-40 \mathrm{~V},-70 \mathrm{~V},-100 \mathrm{~V}$ or $-150 \mathrm{~V}$. The hardness and Young's modulus; (were determined by nanoindentation in a Triboscope Hysitron nanoindenter that was coupled with a Shimadzu SPM 9500 J3 AFM. The effects of the coatings on the tribological properties were evaluated using a Micro Photonics Nanovea CSEM Tribotest ball-on-disk (BOD) with an alumina $\left(\mathrm{Al}_{2} \mathrm{O}_{3}\right)$ ball with diameter of $6 \mathrm{~mm}$, a speed test of $10 \mathrm{~m} / \mathrm{s}$ and a normal load of $1 \mathrm{~N}$. The total distance was $100 \mathrm{~m}$ and the measure was stopped every $25 \mathrm{~m}$ to analyze the wear mechanism using stereoscopic observations. The wear area was measured using an Ambios Technology profilometer to determine the wear rate. The coatings thickness was measured using a scanning electron microscopy (SEM) Philips XL-30. By means of the semi-quantitative SEM/EDS technique, a surface chemical mapping was carried out for identifying the elements presented in the coatings.

\section{RESULTS AND DISCUSSION}

In a previous work, we reported diffraction patterns that showed orientations in the crystallographic planes $\{111\},\{200\},\{220\}$ and $\{311\}$. These patterns exhibited an evident $\{111\}$ preferential orientation. Moreo- 
ver, the intensity of the $\{111\}$ peak decreased as $\mathrm{Al}$ atoms were incorporated into the film, and the film was strongly $\{111\}$ textured for a lower bias voltage $(V s=40 \mathrm{~V})[19]$.

A study of the mechanical and tribological properties of TiAlN coatings, especially the hardness and plasticity, is conducted in this paper using the forming process. This study is important because the damage in tribological processes directly depends on the formation of wear particles, which are initially generated by the contact between asperities when the films are plastically deformed, thus increasing their hardness and producing fractures. Surface damages are generated, which decrease the lifetime of the protective layer [20].

According to the chemical composition analysis carried out by EDS, an increase in the Al concentration depending on $V_{S}$ was exhibited as is presented in table 1 . It was observed a transition between a TiAlN FCC structure toward a hexagonal structure of AIN [21]. The existence of a double HCP-FCC phase was evidenced, caused by the excess of Al, where the FCC structure can be transformed in a HCP structure. This increase determines the type of the TiAlN crystalline structure. PALDEY [21] presented similar results for Al concentration greater than $65 \%$, exhibing FCC-HCP type cells; on the contrary TiAlN coatings presented FCC structure for al percentages lower than $65 \%$.

Table 1: several properties of the TiAlN coatings depending on the bias voltage.

\begin{tabular}{c|c|c|c|c|c|c}
\hline $\begin{array}{c}\text { BIAS VOLTAJE } \\
(\mathbf{V})\end{array}$ & $\mathbf{N}(\mathbf{w t} \%)$ & $\mathbf{A l}(\mathbf{w t} \%)$ & $\mathbf{T i}(\mathbf{w t} \%)$ & $\begin{array}{c}\text { THICKNESS } \\
(\boldsymbol{\mu m})\end{array}$ & $\begin{array}{c}\text { AVERAGE } \\
\text { ROUGHNESS }(\mathbf{n m})\end{array}$ & $\begin{array}{c}\text { AVERAGE } \\
\text { GRAIN SIZE }(\mathbf{n m})\end{array}$ \\
\hline-40 & 2.8 & 25.28 & 71.92 & $1.875 \pm 0.023$ & $51.3 \pm 0.9$ & $51.3 \pm 0.5$ \\
\hline-70 & 3.92 & 31.31 & 64.27 & $1.425 \pm 0.016$ & $83.1 \pm 0.6$ & $83.1 \pm 0.4$ \\
\hline-100 & 4.37 & 35.65 & 60.11 & $1.33 \pm 0.03$ & $87.6 \pm 0.8$ & $87.6 \pm 0.3$ \\
\hline-150 & 6.49 & 40.95 & 52.57 & $1.295 \pm 0.015$ & $96.3 \pm 0.8$ & $96.3 \pm 0.7$ \\
\hline
\end{tabular}

\section{Thickness measurement}

Figure 1 shows AFM images of the samples grown at different bias voltage. From these figures, it was observed that the grain size increases as a function of the bias voltage. Table 1 shows values of roughness, grain size and thickness for layers of TiAlN as a function of bias Vs. Although the sputtering techniques tend to produce denser coatings compared with other techniques used for surface treatments, the triode magnetron sputtering produces an increase in the ionization rate that combined with the high ionic energy and the reference potential of the substrate generate a decrease in the substrate thickness caused by the energy saturation $[18,22]$. The decrease of the thickness can be also attributed to the next factors: the first factor considered is the inverse pulverization process, which normally appears when the high ionic bombardment forces the active species (ionized atoms) to interact with other ions. If the energy level if these ions that bombard the surface is increased a desorption of the surface atoms can be produced. This phenomenon can produce porous and surface defects [17]. The second factor is the increment of the collisions that, due to the ionization degree of the elements, the particles can become neutral and the magnetic field does not affect the movement; due to this effect, the particles do not possess the enough energy for arriving to the surface or for being adsorbed.

The roughness $R a$ depending on bias Vs is shown in table 1, observing an increase from $51.3 \pm 0.4 \mathrm{~nm}$ to $96.3 \pm 0.8 \mathrm{~nm}$. The surface roughness depends meanly on the type of growth and the grain size of the coatings. The increase in the bombardment energy due to the polarization voltage produce an increase in the collisions between the metallic ions inducing an energy loss that is necessary for arriving to the surface, originating an increase Wolmer-Weber type, that is represented as a decrease in the structure density forming porous films. This leads to an increase of the surface roughness. 


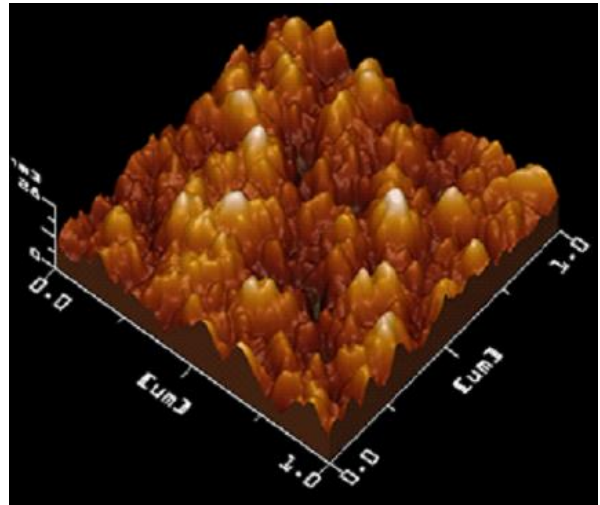

(a)

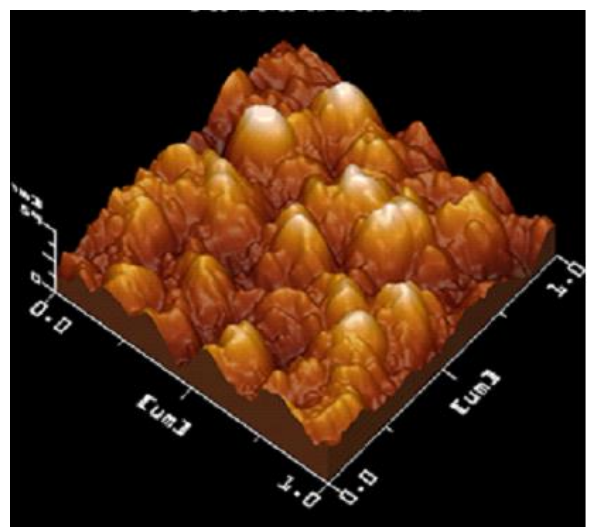

(c)

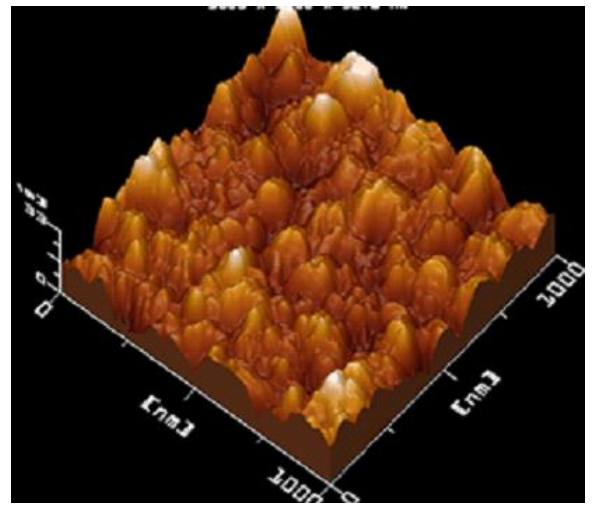

(b)

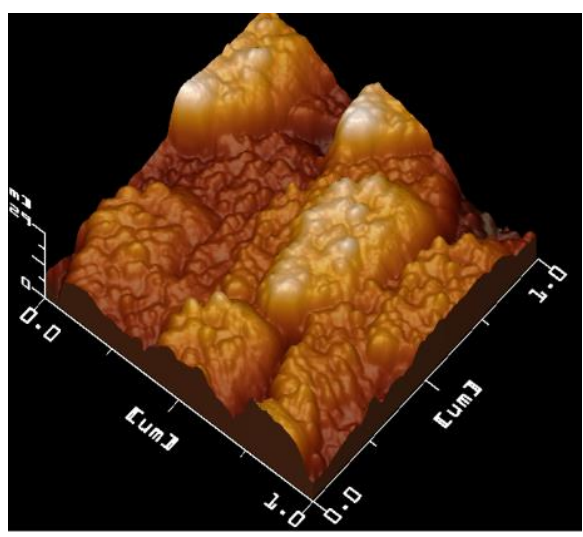

(d)

Figure 1: AFM images of TiAlN coatings for Vs (a) $-40 \mathrm{~V}$, (b) $-70 \mathrm{~V}$, (c) $-100 \mathrm{~V}$ and (d) $-150 \mathrm{~V}$

\section{Mechanical properties}

Fig. 2 shows the hardness and Young's modulus of the TiAlN coatings as functions of the bias voltage. A decrease in the hardness was observed from $32 \mathrm{GPa}$ to $19 \mathrm{GPa}$ as is also shown in table 2. The Young's modulus decreased from $282 \mathrm{GPa}$ to $177 \mathrm{GPa}$ when $V_{s}$ was varied from $-40 \mathrm{~V}$ to $-150 \mathrm{~V}$. These properties depend strongly on the percentage of $\mathrm{Al}$ that is present in the compound [23]. For values of $\mathrm{Al}$ close to 25\%, the samples exhibited a higher hardness, which was caused by the deformation of the FCC structure, confirming the results that were reported by ZHOU [24]. The decrease in hardness as a function of $V_{s}$ can be attributed to two phenomena: the first phenomenon is the increase in the grain size due to the higher mobility of theatoms that arrives to the substrate surface, which can contribute to a reduction in hardness according to the relation described by Hall-Petch. This relation states that a decrease in the grain size increases the material toughness, as described by the LOPEZ [25]. The second phenomenon is the inclusion of Al atoms in the crystallographic lattice, which affects the elasticity modulus of the material when the inclusion is large enough because the stress in the crystalline structure will relax when the material is saturated, thus producing a decrease in the mechanical properties [26].

Table 2: Penetration depth, average load and averad hardness for the samples grown at diferent $V_{S}$.

\begin{tabular}{|c|c|c|c|}
\hline SAMPLE & $\begin{array}{c}\text { PENETRATION } \\
\text { DEPTH }(\mathbf{n m})\end{array}$ & $\begin{array}{c}\text { AVERAGE } \\
\text { LOAD }(\boldsymbol{\mu N})\end{array}$ & $\begin{array}{c}\text { AVERAGE } \\
\text { HARDNESS }(\mathbf{G p a})\end{array}$ \\
\hline 40 & $125.9 \pm 3.069$ & 10000 & $32.2 \pm 2.09$ \\
\hline 70 & $134.7 \pm 3.06$ & 10000 & $27.3 \pm 1.88$ \\
\hline
\end{tabular}




\begin{tabular}{|r|r|r|r|}
\hline 100 & $139.9 \pm 6.7$ & 10000 & $24.2 \pm 3.2$ \\
\hline 150 & $161.8 \pm 1.4$ & 10000 & $19.4 \pm 0.53$ \\
\hline
\end{tabular}

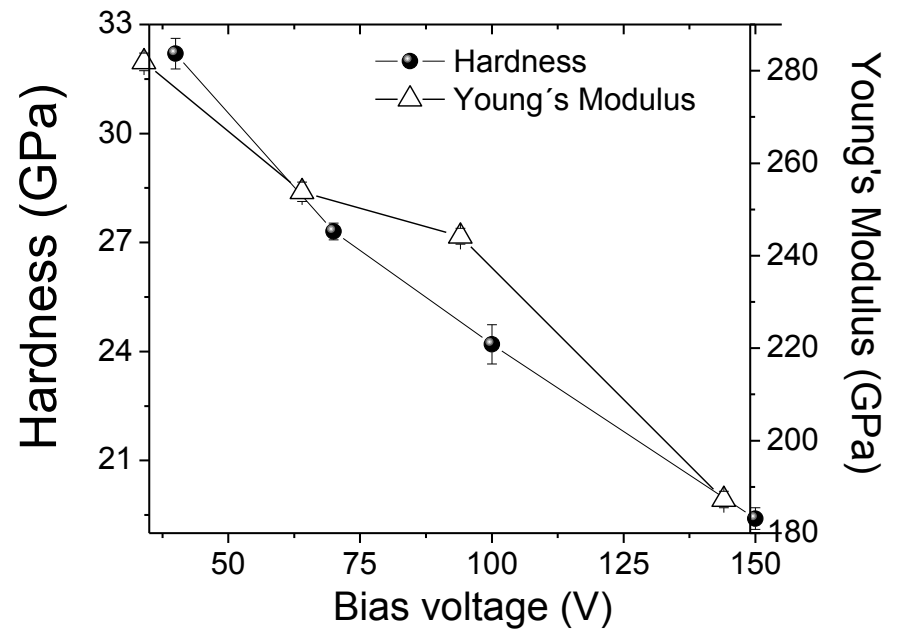

Figure 2: Hardness and Young's modulus as functions of the bias voltage for the TiAlN coatings.

The ratio $H^{3} / E^{2}$ is an important parameter for studying the behavior of tribological properties; this relation is an indicator of the resistance of the layer to plastic deformation [27]. In Fig. 3, the dependence of $H^{3} / E^{2}$ (Fig. 3(a)) and the critical load (Fig. 3(b)) on the bias voltage can be seen. A decreasing tendency with $V_{s}$ was observed, which corresponds to variations in the hardness and Young's modulus. High values of $H^{3} / E^{2}$ can be beneficial for the wear resistance, as was stated by BEAKE, because this behavior provides a greater elastic deformation, thus enabling the coatings to remain in the elastic limit when overloads are applied [28]. A decrease in the critical load from $52 \mathrm{~N}$ to $20 \mathrm{~N}$ was observed. This result is related to the variations in the mechanical properties that were described before and to the adhesion between the coatings and the substrate.
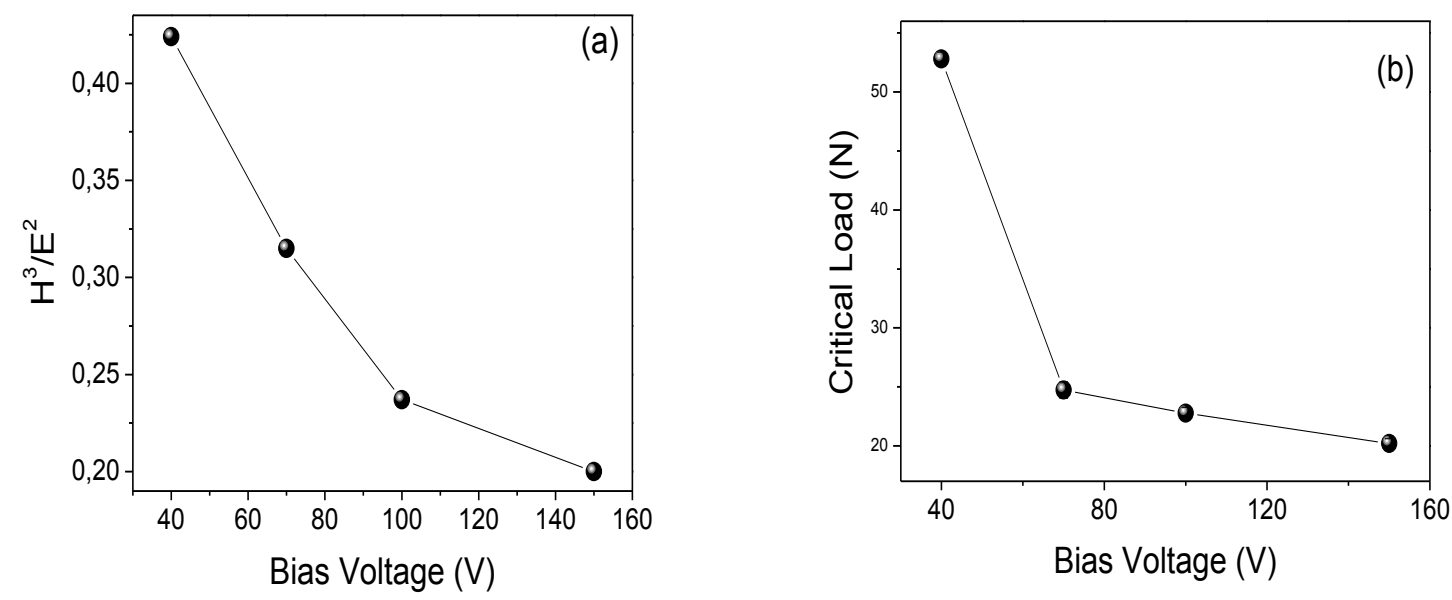

Figure 3: $H^{3} / E^{2}$ relation and critical load as functions of the bias voltage for the TiAlN coatings.

\section{Wear and friction}

The behavior of the coefficient of friction, COF, and the wear (volume of material per distance that was removed during the wear tests) in the case of TiAlN coatings that were grown with various bias voltages 
are shown in Figs. 4(a) and 4(b), respectively. The coating that was grown at $V_{s}=-40 \mathrm{~V}$ exhibits the lowest COF value and the smallest wear. The coatings that were grown under these conditions also exhibit the highest hardness and the lowest roughness. During the ball-on-disc test (BOD), in the first meters of the sliding distance, a polishing of the asperities occurs, which generates particles that are left in the edge of tracks. These particles are possibly produced because of the asperities of the coatings or the natural wear of the counter body. The particles that are on the track can produce greater wear, thus generating delamination and the removal of the protective layer. These particles might lead to a slightly larger volume loss [29].
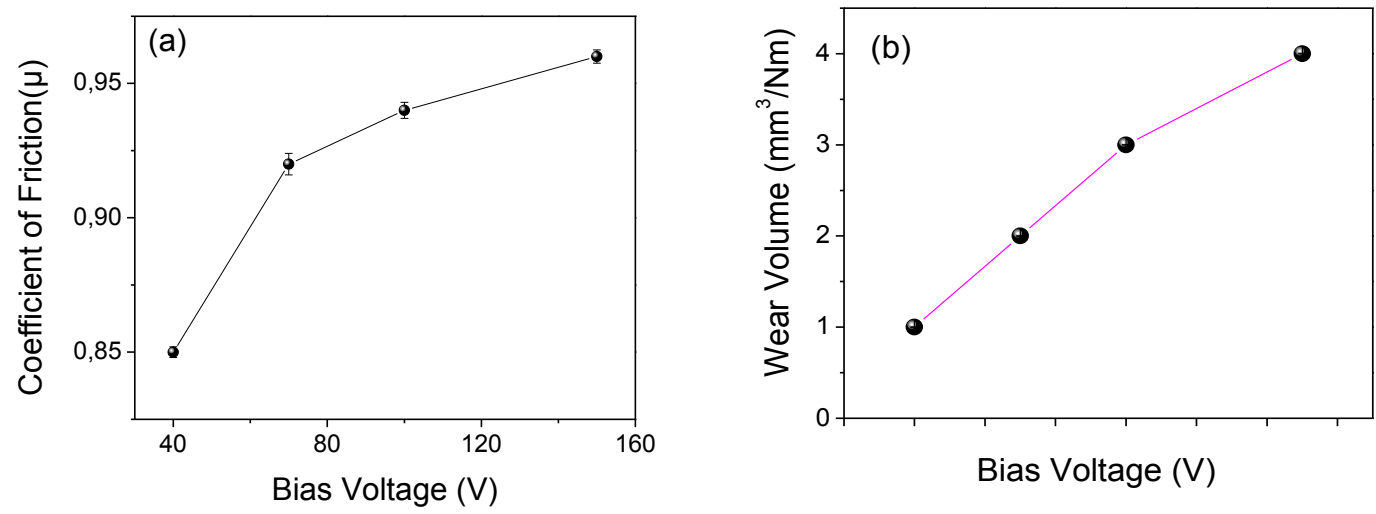

Figure 4: (a) COF and (b) wear as functions of the bias voltage for the TiAlN coatings.

In Fig. 4, the COF dependence on the sliding distance (Fig. 5(a)), the wear track profile (Fig. 5(b)), the micrograph of the wear track at $25 \mathrm{~m}$ (Fig. 5(c)), the EDS spectrum of the track (Fig. 5(d)), the wear tracks at $50 \mathrm{~m}$ (Fig. 5(e)), $75 \mathrm{~m}$ (Fig. 5(f)) and $100 \mathrm{~m}$ (Fig. 5(g)) are shown for the samples that were grown at $V s=-40$ V. A slight increase in the COF (Fig. 5(a)) during the polishing of the asperities can be observed because wear particles are produced. These particles belonged to the coating according to the EDS analysis (Fig. 5(d)). No abrupt transition is observed in the friction curves, i.e., these curves exhibit a steady state. These wear particles have a granular shape, thus causing a rolling effect and the stability of the curve (Fig. 5(a)). According to the micrographs, as the sliding distance is increased, wear particles are accumulated in the tracks, as observed for the sliding distances of 25 and $50 \mathrm{~m}$ (Figs. 5(c) and 5(e)). Two major frictional force sources of the sliding friction are the adhesion force that develops at the contact areas between the two surfaces and the deformation force that is required to plough the asperities of the harder surface through those of the softer surface [30]. At 75 and $100 \mathrm{~m}$ (Figs. 5(f) and 5(g)), a clean surface is observed. The behavior of the coatings over the total sliding distance showed that the coatings can endure the load conditions that were applied because the volume of wear was not high enough to produce the total wear of the coating during the test according to the wear track profile (Fig. 5(b)).
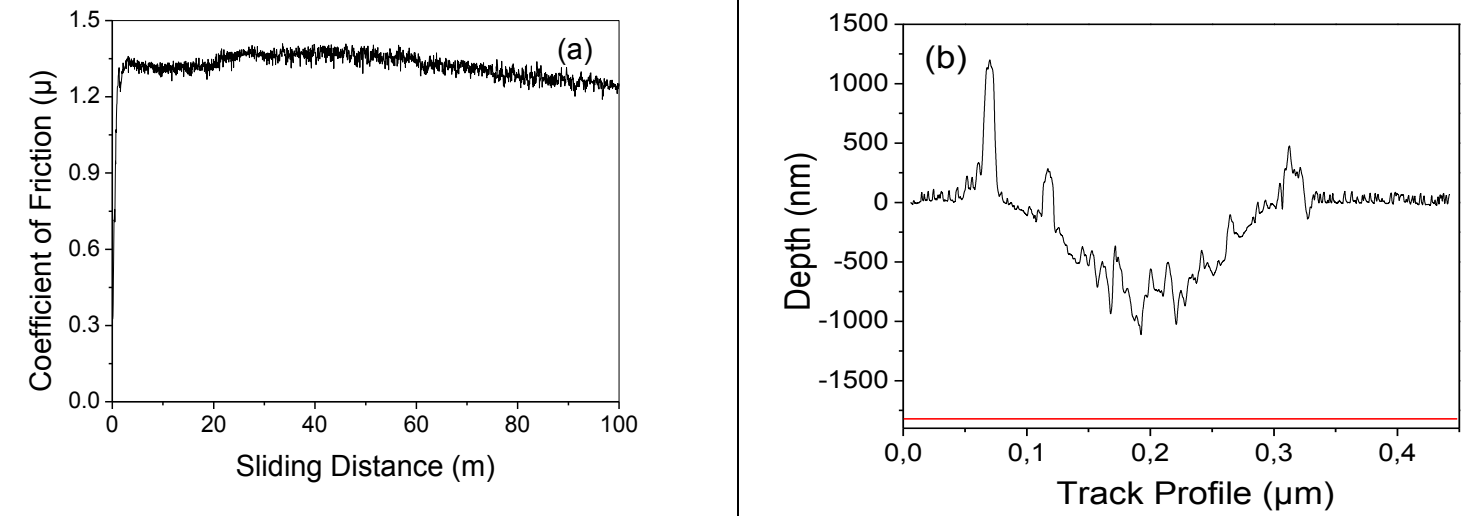


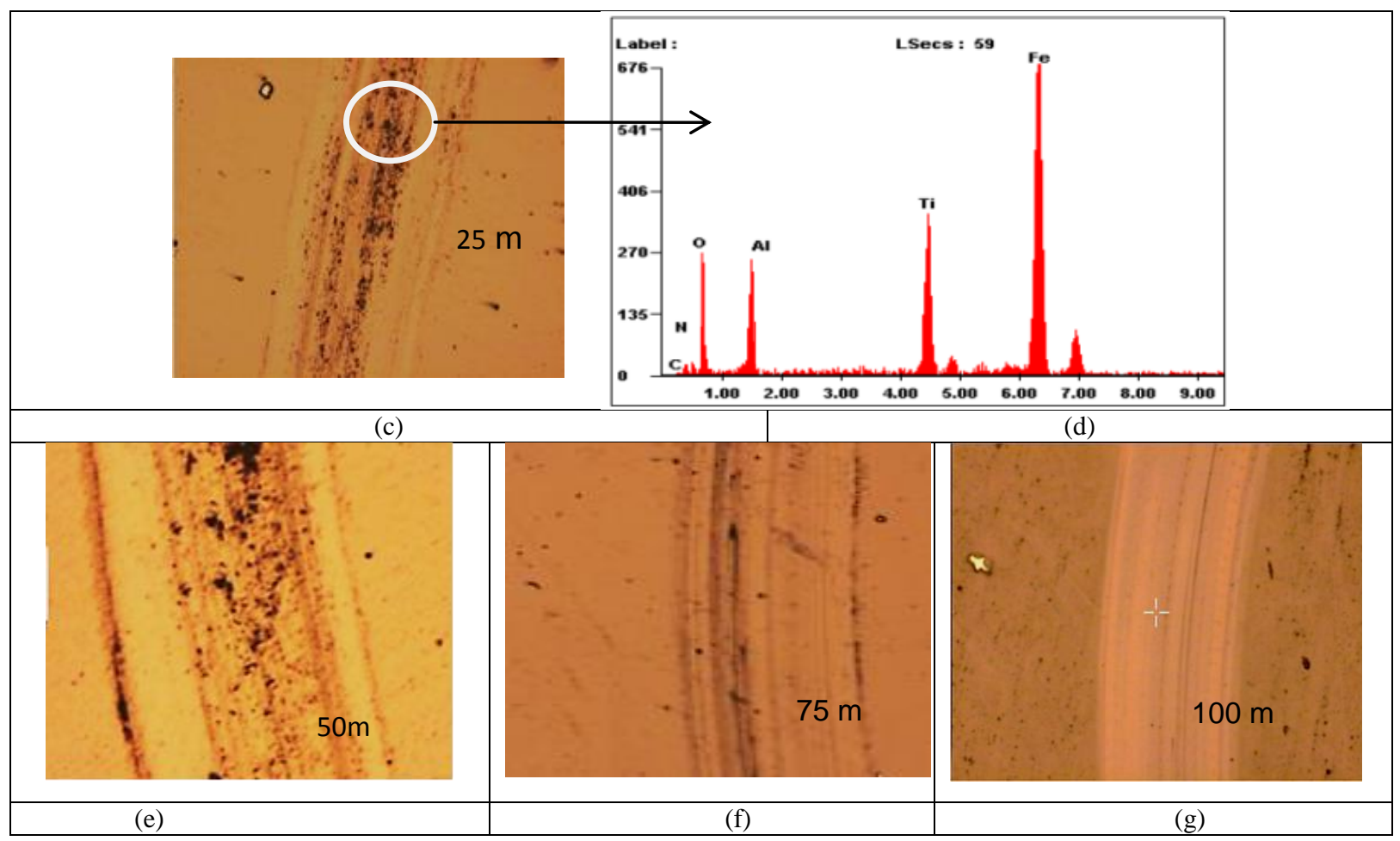

Figure 5: (a) Coefficient of friction (COF) curve for $\mathrm{Vs}=-40 \mathrm{~V}$. (b) the wear track profile. (c) Micrograph of the wear track for the grown sample at $25 \mathrm{~m}$; (d) EDS spectrum of the track. Micrographs of the wear tracks for the grown sample at (e) $50 \mathrm{~m}$, (f) $75 \mathrm{~m}$ and (g) $100 \mathrm{~m}$.

In Fig. 6, the COF dependence on the sliding distance (Fig. 6(a)), the wear track profile (Fig. 6(b)), the micrographs of the wear tracks at $25 \mathrm{~m}$ (Fig. 6(c)), $50 \mathrm{~m}$ (Fig. 6(d)), $75 \mathrm{~m}$ (Fig. 6(e)) and $100 \mathrm{~m}$ (Fig. 6(f)) are shown for the samples that were grown at $V_{s}=-70$ V. In Fig. 6(a), a zone in which the COF is constant (less than $50 \mathrm{~m}$ ) is observed. In this region, the surface asperities of the coatings were plowed by the ball (Fig. 6(c)); afterwards, the surface was polished (Fig. 6(d)). The subsequent decrease in the COF could be caused by the low shear resistance of the highest regions of the surface, which would increase the contact area between the tribological pair. At $70 \mathrm{~m}$ (Fig. 6(e)), an abrupt change in the curve, which is caused by the delamination of the coating, is observed. Stabilization is then observed in the system because the coating was almost totally removed, as shown in Fig. 6(f).

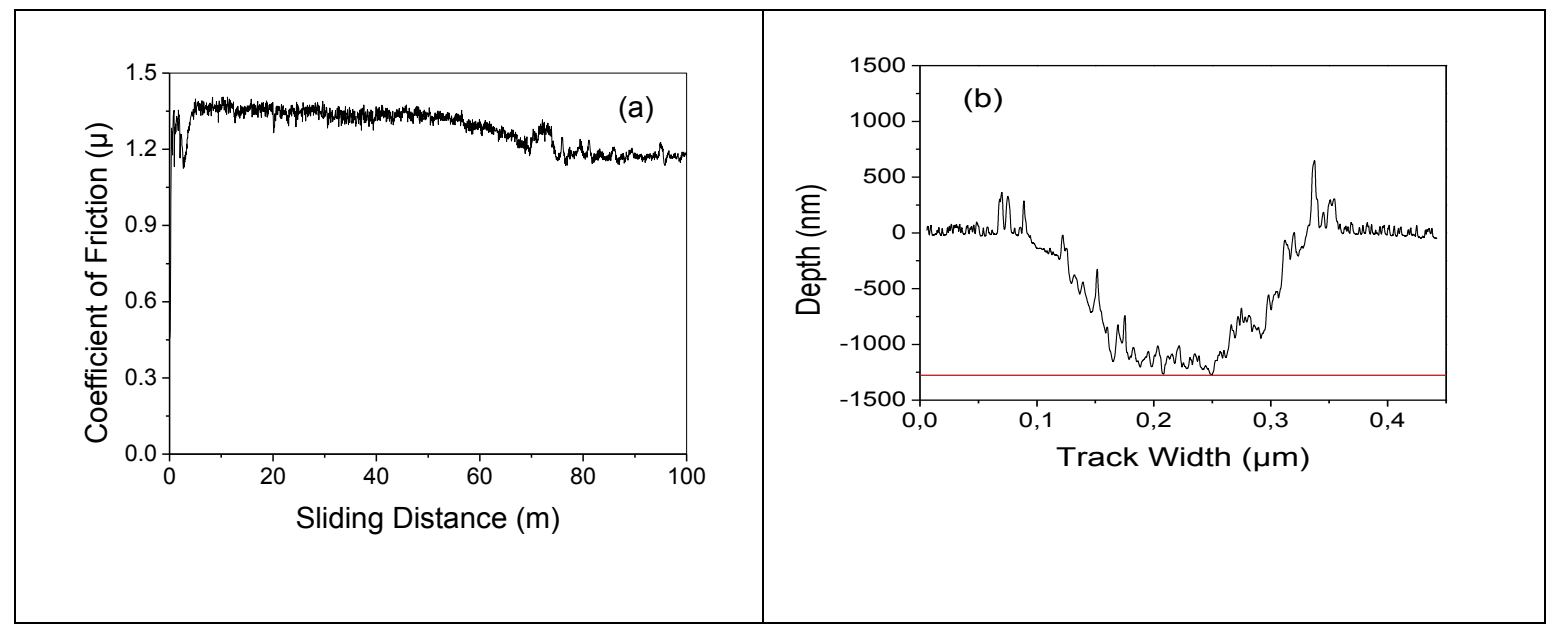




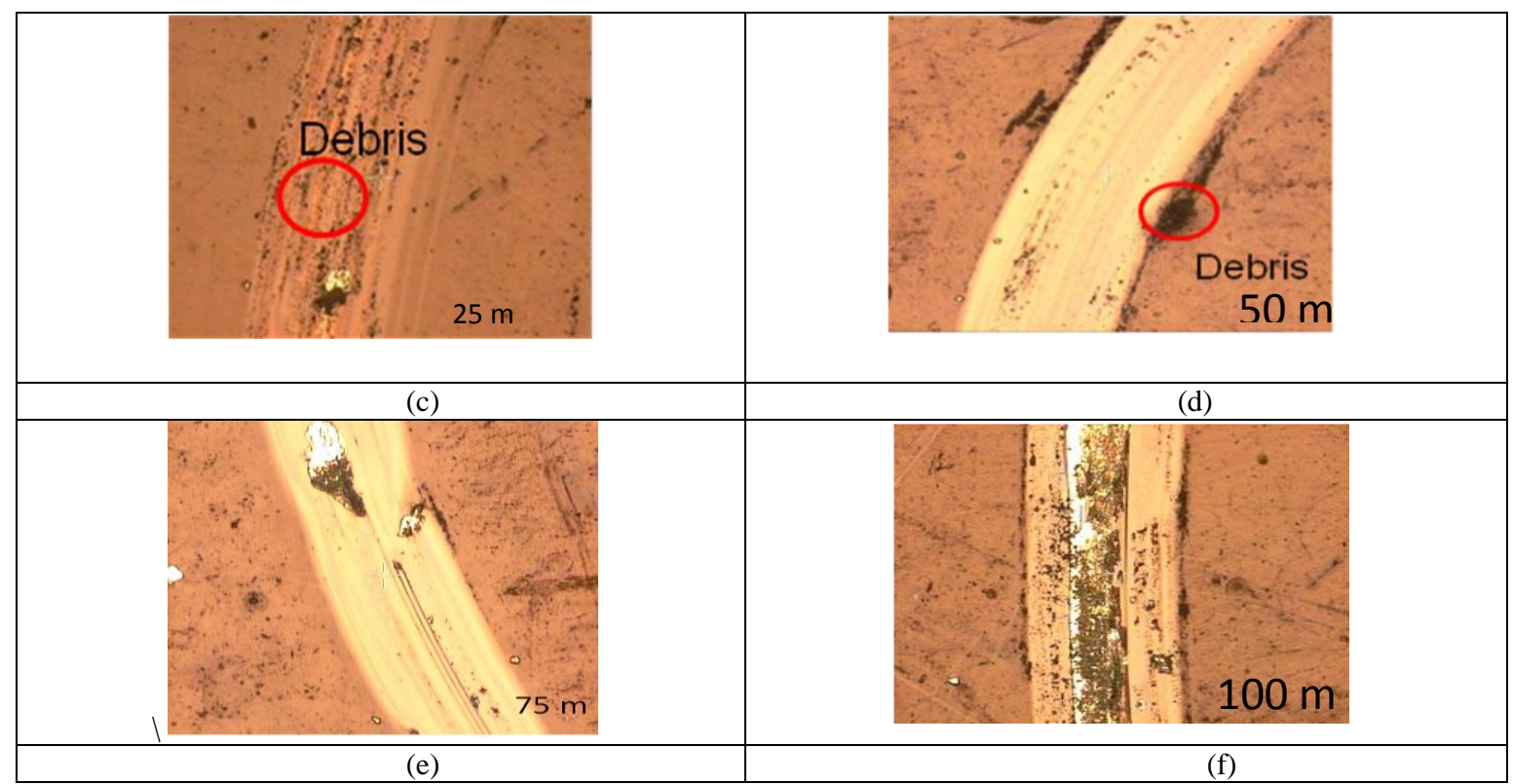

Figure 6: (a) Coefficient of friction (COF) curve for $\mathrm{Vs}=-70 \mathrm{~V}$. (b) the wear track profile. Micrographs of the wear tracks for the grown sample at (c) $25 \mathrm{~m}$, (d) $50 \mathrm{~m}$, (e) $75 \mathrm{~m}$ and (f) $100 \mathrm{~m}$.

In Fig. 7, the COF dependence on the sliding distance (Fig. 7(a)), the wear track profile (Fig. 7(b)) the micrographs of the wear tracks at $25 \mathrm{~m}$ (Fig. 7(c)), $50 \mathrm{~m}$ (Fig. 7(d)), $75 \mathrm{~m}$ (Fig. 7(e)) and $100 \mathrm{~m}$ (Fig. 7(f)) are shown for the samples that were grown at $V_{s}=-100 \mathrm{~V}$. Instability is observed in the COF at approximately $10 \mathrm{~m}$, as shown in Fig. 7(a). This behavior occurs because the angular wear particles are trapped in the tribological pair (Fig. 7(c)). The decrease in the COF is attributed to the removal of these particles and to the presence of a smooth surface (Figs. 7(d) and 7(e)). The abrupt change in the curve after $80 \mathrm{~m}$ indicates the delamination of the layer, and the curve exhibits COF values for the substrate-ball contact. The rapid increase in the friction coefficient may be attributed to the initiation of a gross coating delamination event [30], as observed in the micrograph in Fig. 7(f), in which significant layer damage is shown. This damage is caused by the wear particles in the track, which increase the plowing by a third body [31]. According to observations by DMITRIEV [32], dry friction is largely determined not by the properties of the friction materials of the contacting pair but by the characteristics of the structure and composition of the third body or friction film. As long as third body films separate the first bodies (coating and disc), it is quite clear that the friction will be controlled by the sliding behavior of the films rather than by the properties of the first bodies [33]. This sliding behavior can increase the volume of the wear material, as observed in the wear track profile (Fig. 7(b)). In the current investigation, the friction coefficient was not constant during the test (Fig. 8(a)). The coefficient of friction increased abruptly with compound layer delamination. The friction curve can be divided into two steps. Step 1 is related to the outmatching and smoothing of the sliding surfaces; hence, the friction coefficient decreased. After the removal of the compound layer, a breakthrough was observed in the friction curve. The breakthrough from step 1 to 2 normally indicated that the compound layer was completely worn out, so wear began first in the diffusion zone and then in the Ti-6Al-4V alloy, which produced an average friction coefficient of approximately 0.46 and noisier traces. These noisy traces are associated with the presence of small grooves on the wear surface. RAUTRAY [34] observed 2 steps for the friction behavior of a nitrogen-implanted Ti-6Al-4V alloy. Conversely, MOLINARI [35] reported 3 or 4 steps for the friction behavior of the same nitrided material. 


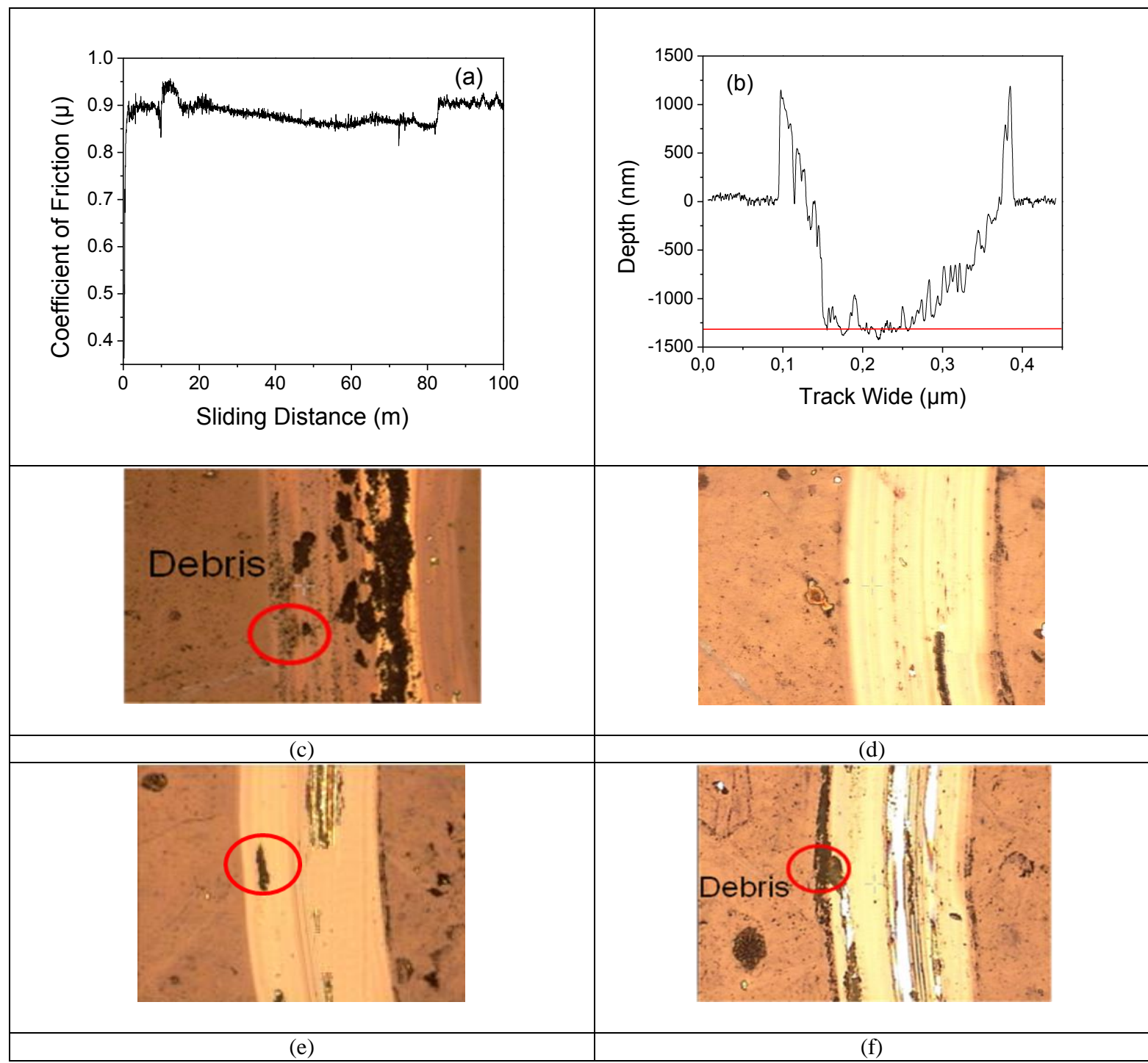

Figure 7: (a) Coefficient of friction (COF) curve for $\mathrm{Vs}=-100 \mathrm{~V}$. (b) the wear track profile. Micrographs of the wear tracks for the grown sample at (c) $25 \mathrm{~m}$, (d) $50 \mathrm{~m}$, (e) $75 \mathrm{~m}$ and (f) $100 \mathrm{~m}$.

In Fig. 8 the COF dependence on the sliding distance (Fig. 8(a)), the wear track profile (Fig. 8(b)), the micrographs of the wear tracks at 25 (Fig. 8(c)), 50 (Fig. 8(d)), 75 (Fig. 8(e)) and $100 \mathrm{~m}$ (Fig. 8(f)) are shown for the samples that were grown at $V_{s}=-150 \mathrm{~V}$. As is shown in Fig. $8(\mathrm{a})$, for the first $30 \mathrm{~m}$, the COF is not stable because of the presence of debris, which is due to the low plastic resistance of the asperities and the high roughness (Fig. 8(c)). The instability of the COF curve increases due to the delamination of the coatings (Fig. 8(d)), thus increasing the number of wear particles. These particles are embedded in the surface, thus increasing the force that is needed for ball movement. After $70 \mathrm{~m}$ (Figs. 8(e) and 8(f)), the COF value stems from the interaction between the substrate and the ball due to the total destruction of the coating. Coating damage is observed after $50 \mathrm{~m}$ of sliding distance. After this distance, all of the coating has been removed. These results are corroborated by the wear track profile (Fig. 8(b)), in which grooves roughly $1.3 \mu \mathrm{m}$ deep are observed. The depth of these grooves is greater than the coating thickness $(1.29 \mu \mathrm{m})$; this result indicates that the coating was totally delaminated and that the wear reached the substrate. The peaks inside the tracks represent the accumulation of particles that contribute to the adhesion and abrasion mechanisms. 


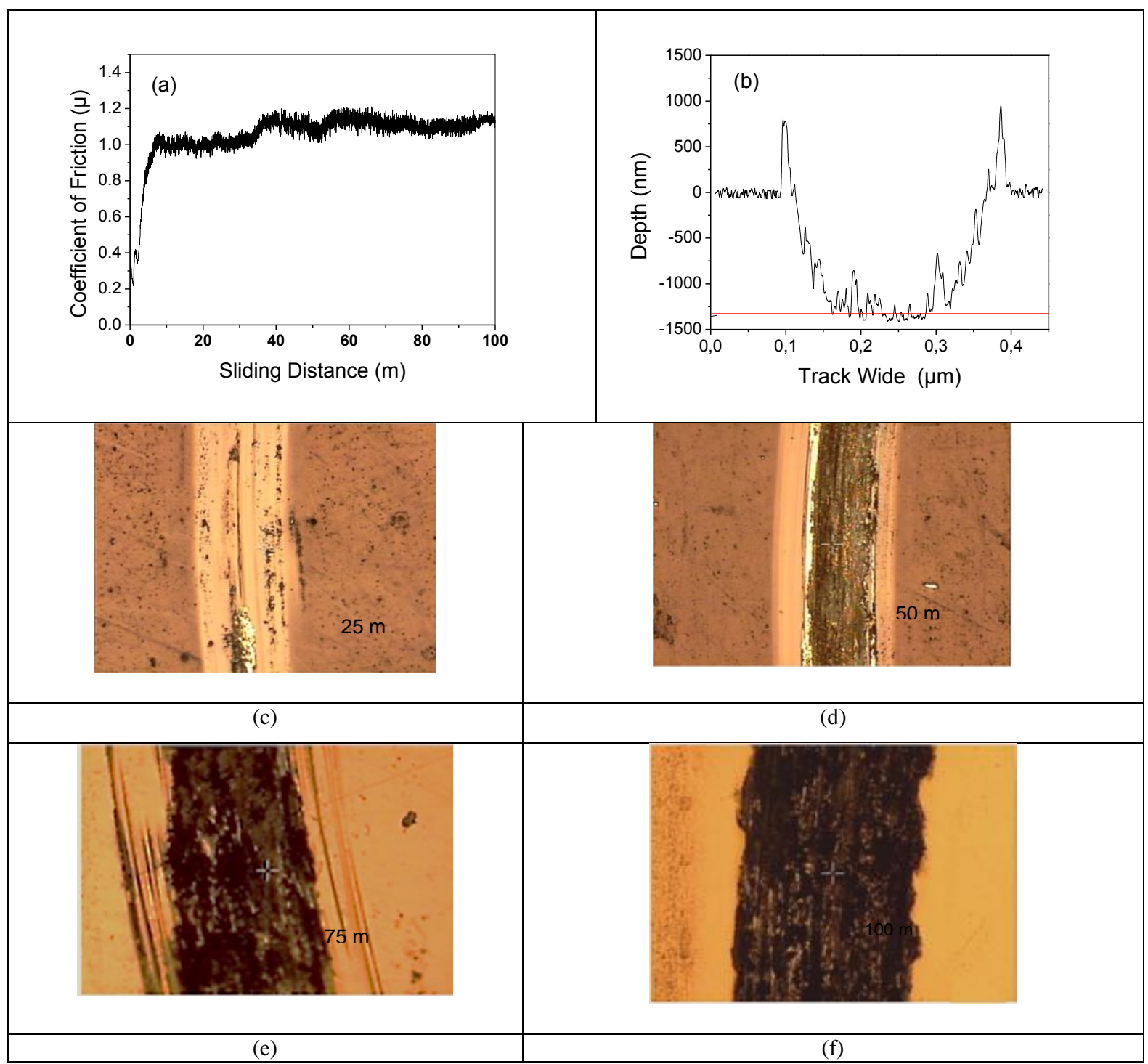

Figure 8: (a) Coefficient of friction (COF) curve for $\mathrm{Vs}=-150 \mathrm{~V}$. (b) the wear track profile. Micrographs of the wear tracks for the grown sample at (c) $25 \mathrm{~m}$, (d) $50 \mathrm{~m}$, (e) $75 \mathrm{~m}$ and (f) $100 \mathrm{~m}$.

In summary, except for the case of the films that were grown at $V_{s}=-100 \mathrm{~V}$, the COF remains stable depending on the sliding distance, the presence of third bodies and film delamination. The films that were grown at $V_{s}=-40 \mathrm{~V}$ exhibited the lowest $\mathrm{COF}$ and wear volume. The coatings that were grown under these conditions also exhibited the highest hardness and the lowest roughness. This behavior can be attributed to the lower energy of the particles that impacted the substrate and films, thus producing less damage, and to the stress relaxation that was caused by the inclusion of smaller atoms ( $\mathrm{Al})$ in the lattice, according to the results presented in [17].

\section{CONCLUSIONS}

TiAlN coatings were produced using the triode magnetron sputtering technique to investigate the effect of the bias voltage on the mechanical and tribological properties of the coatings. It was observed that the hardness and Young's modulus of the coatings decreases as a function of the grain size, following the Hall-Petch relation. An increase in the Al concentration led to reductions in the hardness and Young's modulus; this behavior was associated with the saturation of the crystalline structure. The coefficient of friction (COF) values oscillated between 0.7 and 0.9 ; these values are in agreement with the results that were previously reported in the literature for this material. The most dominant wear mechanism was the abrasion that was associated with the wear particles, which act as a third body. This analysis enables the conclusion that the film that was grown at $\mathrm{Vs}=-40 \mathrm{~V}$ exhibited the best mechanical and tribological behavior. 


\section{ACKNOWLEDGMENTS}

The authors gratefully acknowledge the financial support of the División para la Investigación de la Universidad Nacional de Colombia Sede Manizales (DIMA) under the project "Producción y caracterización de recubrimientos con aplicaciones industriales y biocompatibles."

\section{BIBLIOGRAPHY}

[1] KIM, D., CAO, D., BRYANT, M.D., et al., "Tribological study of microbearing for MEMS applications", Journal of Tribology, v. 127, n.3, pp. 537-547, Jan. 2005.

[2] MYSHKIN, N.K., "Devices for Tribotests at Micro/Nano Scale", Tribology Industry, v. 26, n. 2, pp. 1520. 2004.

[3] LEYENDECKER, T., LEMMER, O., ESSER, S., et al., "The development of the PVD coating TiAlN as a commercial coating for cutting tools", Surface and Coatings Technology, v. 48, n.1, pp. 175-178, Nov. 1991.

[4] UPADHYAY, R. K., KUMARASWAMIDHAS, L.A., "Friction behaviour of TiN, CrN coating on AISI 4320 steel substrate", International Journal Mechanical Engineering and Robotics Research, v. 2, n. 1, pp. 107-109, Jan. 2013.

[5] RECCO, A.A.C., TSCHIPTSCHIN, A.P., "Structural and Mechanical Characterization of Duplex Multilayer Coatings Deposited onto H13 Tool Steel", Journal of Materials Research and Technology, v. 1, pp. 182-188, Oct. 2012.

[6] SVEEN, S., ANDERSSON, J.M., M'SAOUBI, R., OLSSON M., "Scratch adhesion characteristics of PVD TiAlN deposited on high speed steel, cemented carbide and PCBN substrates", Wear, v.308, pp. 133141, Sep. 2013.

[7] RAMADOSS, R., KUMAR, N., PANDIAN, R., et al., "Tribological properties and deformation mechanism of TiAlN coating sliding with various counterbodies", Tribology International, v. 6, pp. 143-149, May 2013.

[8] JEONA, S., VAN TYNE, C.J., LEE, H., "Degradation of TiAIN coatings by the accelerated life test using pulsed laser ablation", Ceramics International, v. 40, pp. 8677-8685, Jan. 2014.

[9] TILLMANN, W., SPRUTE, T., HOFFMANN, F., CHANG, Y., et el., "Influence of bias voltage on residual stresses and tribological properties of TiAlVN-coatings at elevated temperatures", Surface and Coatings Technology, v. 231, pp. 122-125, March 2013.

[10] YUAN, L., GAO, Y., ZHANG, W., et al., "Effect of Negative Bias Voltage on Corrosion Resistance of TiN Coating Deposited by MAIP”, Advanced Materials Research, v. 399-401, pp. 1898-1902, Nov. 2011.

[11] DETOR, A.J., HODGE A.M., CHASON E., et al., "Stress and microstructure evolution in thick sputtered films", Acta Materialia, v. 57, pp. 2055-2065, Journal of Vacuum Science \& Technology A, v. 21, pp. 117-128, Feb. 2009.

[12] LJUNGCRANTZ, H., HULTMAN L., et al., "Ion induced stress generation in arc-evaporated TiN films", Journal of Applied Physics, v. 78, n.2, pp. 832-837, July 1995.

[13] DETOR, A.J., HODGE, A.M., CHASON, E., et al., "Stress and microstructure of thick sputtered films". Acta Materialia, v. 57, n. 7, pp. 2055-2065, April 2009.

[14] ZHAO H., WANG, X., LIU Q., et al, "Structure and wear resistance of TiN and TiAlN coatings on AZ91 alloy deposited by multi-arc ion plating", Transactions of Nonferrous Metals Society of China, v. 20, pp. 679-682, Jan. 2010

[15] ALIAJ, F., SYLA, N., "Influence of Al content and bias voltage on the microstructure of Ti1-xAlxN hard coatings", Journal of Engineering and Applied Sciences, v. 5, pp. 394-402, 2010.

[16] KONG, Q., JI, L., LI, H., et al., "Influence of substrate bias voltage on the microstructure and residual stress of $\mathrm{CrN}$ films deposited by medium frequency magnetron sputtering", Materials Science and Engineering: $B$, v. 176, n. 11, pp. 850-854, June 2011.

[17] DEVIA, D.M., RESTREPO-PARRA, E., ARANGO, P.J., et al., "TiAlN coatings deposited by triode magnetron sputtering varying the bias voltage”, Applied Surface Science, v. 257, n. 14, pp. 6181-6185, May 2011.

[18] RECCO, A.C.C., OLIVEIRA, I.C., MASSI, M., et al., "Adhesion of reactive magnetron sputtered TINx and TICy coatings to AISI H13 tool steel", Surface and Coatings Technology, v. 202, n. 4, pp. 1078-1083, 
Dec. 2007.

[19] Devia, D.M., Restrepo-Parra, E., Velez-Restrepo, J.M., "Structural and Morphological Properties of Titanium Aluminum Nitride Coatings Produced by Triode Magnetron Sputtering”, Ingeniería y Ciencia, v. 10, n. 20, pp. 51-64, July 2014.

[20] HUTǍ̌, P., NÁHLÍK, L., ŠESTÁKOVÁ, L., et al., “A fracture mechanics assessment of surface cracks existing in protective layers of multi-layer composite pipes", Composite Structures, v. 92, n. 5, pp. 11201125, April 2010.

[21] PALDEY, S., DEEVI, S.C., "Single layer and multilayer wear resistant coatings of (Ti,Al)N: a review", Materials Science and Engineering: A, v. 342, n. 1, pp. 58-79, Feb. 2003.

[22] CAICEDO, J.C., AMAYA, C., GÓMEZ, M.E., et al., "Dependencia de las propiedades mecánicas de TiC1-xNx con el voltaje Bias", Revista Latinoamericana de Metalurgia y Materiales, v. 4, pp. 1487-1492, July 2009.

[23] YOON, J.S., LEE, H.Y., HAN, J.G., et al., "The effect of Al composition on the microstructure and mechanical properties of WC-TiAlN superhard composite coating", Surface and Coatings Technology, v.142144, pp. 596-602, July 2001.

[24] ZHOU, M., MAKINO, Y., NOSE, M., et al., "Phase transition and properties of Ti-Al-N thin films prepared by r.f.-plasma assisted magnetron sputtering", Thin solid Films, v. 339, n. 1, pp. 203-208, Feb. 1999.

[25] LÓPEZ, J.M., GORDILLO-VÁZQUEZ, F.J., BÖHME, O., et al., "Low grain size TiN thin films obtained by low energy ion beam assisted deposition", Applied Surface Science, v. 173, n. 3, pp.290-295, March 2001.

[26] EBERHARDT, A.W., PANDEY, R., WILLIAMS, J.M., et al., "The roles of residual stress and surface topography on hardness of Ti implanted Ti6Al4V", Materials Science and Engineering: A, v. 229, n. 1, pp. 147-155, June 1997.

[27] BEAKE, B.D., VISHNYAKOV, V.M., HARRIS, A.J., "Relationship between mechanical properties of thin nitride-based films and their behaviour in nano-scratch tests", Tribology International, v. 44, n. 4, pp. 468-475, April 2011.

[28] BEAKE, B.D., RANGANATHAN, N., "An investigation of the nanoindentation and nano/microtribological behaviour of monolayer, bilayer and trilayer coatings on cemented carbide", Materials Science and Engineering: A, v. 423, n. 1, May 2006.

[29] BAKSHI, S.R., WANG, D., PRICE, T., et al., "Microstructure and wear properties of aluminum/aluminum-silicon composite coatings prepared by cold spraying", Surface and Coatings Technology, v. 204, n. 4, pp. 503-510, Nov. 2004.

[30] FUJISAWA, N., SWAIN, M.V., JAMES, N.L., et al., "Carbon coating of Ti-6Al-4V for reduced wear in combined impact and sliding applications", Tribology International, v. 36, n. 12, pp. 873-882, Dec. 2003.

[31] FU, Y., WEI, J., BATCHELOR, A.W., "Some considerations on the mitigation of fretting damage by the application of surface-modification technologies", Journal of Materials Processing Technology, v. 99, n. 1, pp. 231-245, March 2000.

[32] DMITRIEV, A.I., ÖSTERLE, W., KLOß, H., ORTS-GIL, G., "A study of third body behaviour under dry sliding conditions comparison of nanoscale modelling with experiment", Estonian Journal of Engineering, v. 18, pp. 270-278, July 2012.

[33] HINRICHS, R., SOARES MARCIO, R.F., LAMB, R.G., VASCONCELLOS, M.A.Z., "Phase characterization of debris generated in brake pad coefficient of friction tests", Wear, v. 270, pp. 515-519, March 2011.

[34] RAUTRAY, T. R., NARAYANAN, R., KIM, K. H., "Ion implantation of titanium based biomaterials", Progress in Materials Science, v. 56, pp. 1137-1177, March 2011.

[35] MOLINARI, A., STRAFFELINI, G., TESI, B., et al., "Effects of load and sliding speed on the tribological behaviour of Ti6Al4V plasma nitrided different temperatures", Wear, v. 2003-204, pp. 447-454, March 1997. 